\title{
Burden and future projection of revision Total hip Arthroplasty in South Korea
}

Jung-Wee Park ${ }^{1 \dagger}$, Seok-Hyung Won ${ }^{1 \dagger}$, Sun-Young Moon ${ }^{2}$, Young-Kyun Lee ${ }^{1 *} \mathbb{D}$, Yong-Chan $\mathrm{Ha}^{3}$ and Kyung-Hoi Koo ${ }^{1,4}$

\begin{abstract}
Background: The annual number of hip arthroplasties is increasing combined with the aging population worldwide. In accordance with the increasing number of primary hip arthroplasties, the number of revision total hip arthroplasties (THAs) is expected to increase. The incidence and burden of revision THAs in the United States and have been reported by registry studies. To identify potential differences according to ethnics and regional practice, it is important to obtain data from East Asia. Nevertheless, there has been a lack of studies on the burden and future projection of revision THA based on a large-scale database in East Asia. The purpose of this study was to evaluate annual incidence and burden of revision THAs and to project the future burden in South Korea.
\end{abstract}

Methods: We identified primary THAs, primary hemiarthroplasties (HAs) and revision THAs, which were performed from 2010 to 2018, using database of Health Insurance and Review and Assessment (HIRA); nation-wide medical claim system of South Korea. The annual incidence rates (per 100,000) of primary THA, primary HA and revision THA, and the annual burden of revision THA; the number of revision THAs divided by the sum of primary hip arthroplasties and revision THAs, were calculated. The future burden of revision THAs were projected through 2030 using generalized linear model with Quasi-poisson regression.

Results: During the 9-year period, the annual incidences of primary THA, primary HA and revision THA increased by 47, 29 and 3\%, respectively, while the revision burden decreased from 0.13 to 0.10 . Compared to 2018 , the annual incidences of primary THA, HA, and revision THA were projected to increase by $7.2,2.3$ and $1.1 \%$ per year, respectively, whereas the burden of revision THA was projected to decrease to 0.07 in 2030.

Conclusion: Trends of revision THA in South Korea were similar with those of national registry studies from the United States. The annual incidence of revision THA has steadily increased, whereas its burden has decreased. Findings of our study could be used for epidemiological comparison between Western countries and East Asia as well as for the establishment of medical policies of revision THA in East Asian countries.

Keywords: Hip, Arthroplasty, Revision, Burden, East Asia, South Korea

\footnotetext{
*Correspondence: ykleemd@gmail.com

†Jung-Wee Park and Seok-Hyung Won contributed equally to this study, and should be considered as co-first authors.

'Department of Orthopaedic Surgery, Seoul National University Bundang Hospital, Seongnam, South Korea

Full list of author information is available at the end of the article
}

(c) The Author(s). 2021 Open Access This article is licensed under a Creative Commons Attribution 4.0 International License, which permits use, sharing, adaptation, distribution and reproduction in any medium or format, as long as you give appropriate credit to the original author(s) and the source, provide a link to the Creative Commons licence, and indicate if changes were made. The images or other third party material in this article are included in the article's Creative Commons licence, unless indicated otherwise in a credit line to the material. If material is not included in the article's Creative Commons licence and your intended use is not permitted by statutory regulation or exceeds the permitted use, you will need to obtain permission directly from the copyright holder. To view a copy of this licence, visit http://creativecommons.org/licenses/by/4.0/ The Creative Commons Public Domain Dedication waiver (http://creativecommons.org/publicdomain/zero/1.0/) applies to the data made available in this article, unless otherwise stated in a credit line to the data. 


\section{Background}

Total hip arthroplasty (THA) is one of the most effective orthopedic procedures and has been utilized as the treatment of choice for the patients with advanced osteoarthritis of the hip [1-4]. However, THA is associated with early and late failures and inevitably necessitates revision surgeries, which is a socioeconomic burden worldwide [5-8].

In the United States, the annual number of revision THA has steadily increased, $[6,9]$ but the burden of revision THA; the proportion of revision THAs to overall sum of hip arthroplasties; primary THAs, primary HAs and revision THAs, was disconcerting since 1990s [10].

There might be regional differences in the burden of revision THA according to ethnicity, implant design, fixation method; cemented versus cementless, and bearing surface [11].

Number of studies outside the United States reported the annual incidence of revision THA [12-16]. Epidemiological trend similar to the United States; increase in the number of revision THA and decrease in the burden of revision THA, was observed in other countries including Australia, New Zealand, England, Wales and Sweden except for Norway [17].

Nevertheless, there is lack of epidemiological study of revision THA in East Asia, which is necessary for regional comparison of the revision THA burden between Western countries and East Asia and for awareness of worldwide tendency.

The purpose of this study was 1) to analyze the burden of hip arthroplasty including primary THA, HA and revision THA from 2010 to 2018 and 2) to provide a future projection of these procedures to 2030 in South Korea.

\section{Methods}

\section{Source of database}

This is a retrospective study using secondary registerbased data analysis. The Korean Health Insurance and Review and Assessment (HIRA) database includes medical claims from entire South Korean institutions.
Ninety-seven percent of South Korean population is obliged to register into the Korea National Health Insurance Program (KNHIP).

The remaining 3\% of the population is covered by the Medical Aid program, which is paid by the government. Data of patients under the.

Medical Aid program are submitted to HIRA in the same manner as KNHIP. Therefore, the HIRA database included the entire South Korean population.

The HIRA database contains demographics, diagnoses, procedures and prescriptions of all THA patients in South Korea.

We identified primary THAs, primary HAs and revision THAs, which had been done from January 2010 to May 2014 in South Korea, using Electronic Data Interchange (EDI) codes of THA (N0711) and hemiarthroplasty (HA) (N0715).

Since June 2014, the Korean National Health Insurance Service (NHIS) added complex surgical procedure codes (total joint arthroplasty-hip (complex) (N2070) and hemiarthroplasty-hip (complex) (N2710)) for the specific 21 complex conditions for reimbursement of an additional cost to the medical institute (Supplement. 1). THAs and HAs, which had been done from June 2014 to December 2018, were identified using 4 procedure codes (N0711, N2070, N0715, and N2710).

Revision THAs were identified using procedural codes of simple revision THA (N1711, N1721, N1715, N1725) and complex revision THA (N3710, N3720, N4710, N4720).

\section{Data and statistical analyses}

The numbers and crude incidence rates (per 100,000) of THA, HA, and revision THA procedures were calculated according to age and gender. Annual incidence rate of each arthroplasty was calculated by dividing the number of each procedure at each year with corresponding yearspecific South Korean population. The annual population data were acquired from database of the Korean Statistical Information Service. Then, the incidence rate

Table 1 Change of hip arthroplasties in South Korea from 2010 to 2018

\begin{tabular}{|c|c|c|c|c|c|c|c|c|c|}
\hline \multirow[t]{2}{*}{ Type of Surgery } & \multicolumn{9}{|c|}{ No. of procedures } \\
\hline & 2010 & 2011 & 2012 & 2013 & 2014 & 2015 & 2016 & 2017 & 2018 \\
\hline Primary THA & 7657 & 7917 & 8673 & 9278 & 9520 & 10,357 & 11,036 & 11,227 & 11,548 \\
\hline $\mathrm{HA}$ & 10,918 & 11,532 & 12,561 & 12,949 & 12,941 & 13,737 & 13,420 & 13,613 & 14,408 \\
\hline Revision THA & 2728 & 2671 & 2777 & 2701 & 2752 & 2826 & 2875 & 3032 & 2870 \\
\hline Population & $50,515,666$ & $50,734,284$ & $50,948,272$ & $51,141,463$ & $51,327,916$ & $51,529,338$ & $51,696,216$ & $51,778,544$ & $51,826,059$ \\
\hline Primary THA incidence & 15.16 & 15.60 & 17.02 & 18.14 & 18.55 & 20.10 & 21.35 & 21.68 & 22.28 \\
\hline HA incidence & 21.61 & 22.73 & 24.65 & 25.32 & 25.21 & 26.66 & 25.96 & 26.29 & 27.80 \\
\hline Revision THA incidence & 5.40 & 5.26 & 5.45 & 5.28 & 5.36 & 5.48 & 5.56 & 5.86 & 5.54 \\
\hline Burden of revision THA & 0.13 & 0.12 & 0.12 & 0.11 & 0.11 & 0.10 & 0.10 & 0.10 & 0.10 \\
\hline
\end{tabular}




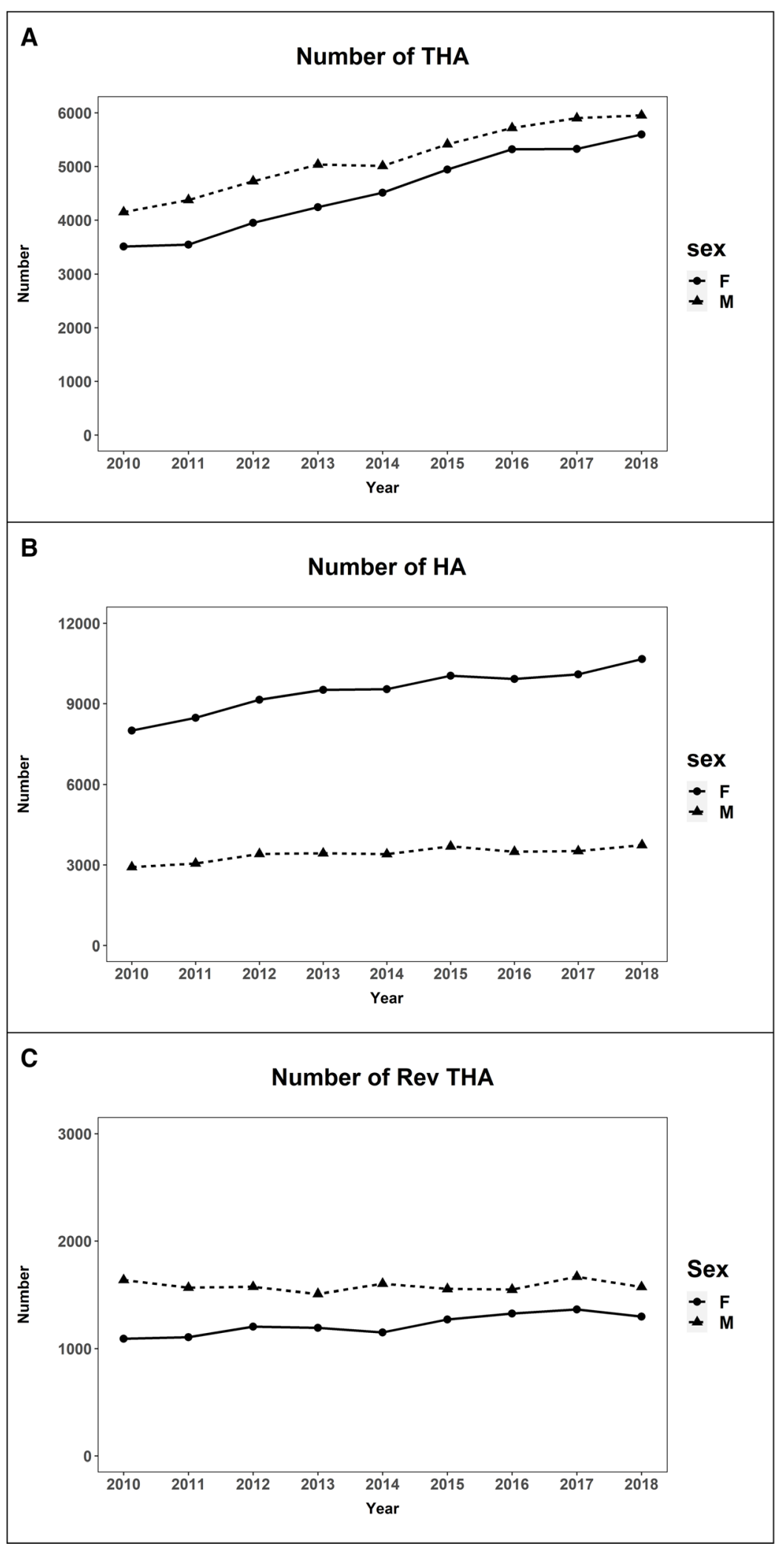

Fig. 1 Number of primary total hip arthroplasty $\mathbf{a}$, hemiarthroplasty $\mathbf{b}$, and revision total hip arthroplasty $\mathbf{c}$ in each gender (THA, total hip arthroplasty; HA, hemiarthroplasty; RevTHA, revision total hip arthroplasty) 
per 100,000 person-year was calculated. The annual rates were stratified according to age and gender.

The burden of revision THA was defined as the proportion of revision THAs to overall sum of hip arthroplasties; primary THAs, primary $\mathrm{HAs}$ and revision THAs [18]. The future projection of THA, HA and revision THAs through 2030 were calculated by using generalized linear model with Quasi-poisson regression. Demographics-based projections through 2030 were obtained from the Korean Statistical Information Service.

\section{Results}

Annual incidences of primary THA, primary HA and revision THA from 2010 to 2018

From 2010 to 2018, 87,213 primary THAs, 116,079 primary HAs, and 25,232 revision THAs were done in South Korea. The number of each surgery at each year is summarized in Table 1.

During the 9-year period, the annual crude incidence of primary THA and that of primary HA increased by $47 \%(15.2 / 100,000$ in 2010 to $22.3 / 100,000$ in 2018) and $29 \%(21.6 / 100,000$ in 2010 to $27.8 / 100,000$ in 2018$)$, respectively. Nevertheless, the annual incidence rate of revision THA remained stable at an average of 5.5/100,000 (range, 5.4-5.9/100,000) (Fig. 1), and the burden of revision THA decreased from 0.13 to 0.10 (Table 1 ).

Overall, $86 \%$ of primary HA patients were $\geq 70$ years of age, whereas $50 \%$ of primary THA patients and $29 \%$ of revision THA patients were $<60$ years of age (Table 2).

The annual number of primary THA increased in age groups of $50-59$ years, 60-69 years, $70-79$ years and $\geqq$ 80 years, whereas the annual number of HA increased only in the age group of $\geqq 80$ years. The annual number of revision THA slightly increased in age groups of 7079 years and $\geqq 80$ years (Fig. 2 ).
In 2018, the peak age of primary THA was 50-59 years in men and 70-79 years in women. The number of HA abruptly increased after 50 years, especially in women. The peak age of revision THA was 60-69 years in men and 70-79 years in women (Fig. 3).

The burden of revision THA slightly decreased from 0.13 in 2010 to 0.10 in 2018 .

\section{Projection of annual numbers of primary THA, primary HA and revision THA to 2030}

In our prediction model, the numbers of primary THA and HA were predicted to increase to 21,465 (95\% confidence interval (CI) 16,792 - 27,451) and 18,384 (95\% CI 16,162 - 20,918), respectively, while the number of revision THA was predicted to be 3241 (95\% CI 3042 3454 ) in 2030 (Fig. 4). Compared to 2018, the annual incidences of primary THA, HA, and revision THA were projected to increase by $7.2,2.3$ and $1.1 \%$ per year, respectively, whereas the burden of revision THA was projected to decrease to 0.07 in 2030 .

\section{Discussion}

Our study showed that the annual crude incidences of primary THA and primary HA increased by 47 and 29\%, respectively, whereas and revision THA increased by only $3 \%$ and the burden of revision THA decreased from 0.13 to 0.10 during the period from 2010 to 2018 in South Korea. The burden of revision THA was projected to decrease to 0.07 in 2030.

These trends were similar with those of previous national registry studies from the United States, United Kingdom and Taiwan (Table 3) [9, 13, 14, 19, 20].

In the study of Wolf et al. the revision burden reduced from 0.20 in 1991-1993 to 0.17 in 2006-2008 [19]. Another study by Schwartz et al. showed similar decrease

Table 2 Demographic characteristic of patients who had hip replacements from 2010 to 2018 in Korea

\begin{tabular}{|c|c|c|c|}
\hline & Primary THA $(n=87,213)$ & $\mathrm{HA}(n=116,079)$ & Revision THA $(n=25,232)$ \\
\hline \multicolumn{4}{|l|}{ Gender (\%) } \\
\hline Male & 46,276 (53\%) & $30,664(26 \%)$ & 14,224 (56\%) \\
\hline Female & $40,937(47 \%)$ & $85,415(74 \%)$ & $11,008(44 \%)$ \\
\hline \multicolumn{4}{|l|}{ Age category } \\
\hline 10-19 years & 156 & 24 & 21 \\
\hline 20-29 years & 1952 & 71 & 102 \\
\hline 30-39 years & 6628 & 330 & 540 \\
\hline 40-49 years & 12,639 & 1069 & 1995 \\
\hline 50-59 years & 21,968 & 3512 & 4600 \\
\hline 60-69 years & 20,807 & 11,270 & 6975 \\
\hline 70-79 years & 18,000 & 42,723 & 7757 \\
\hline$\geq 80$ years & 5063 & 57,080 & 3109 \\
\hline
\end{tabular}

THA total hip arthroplasty, HA hemiarthroplasty 


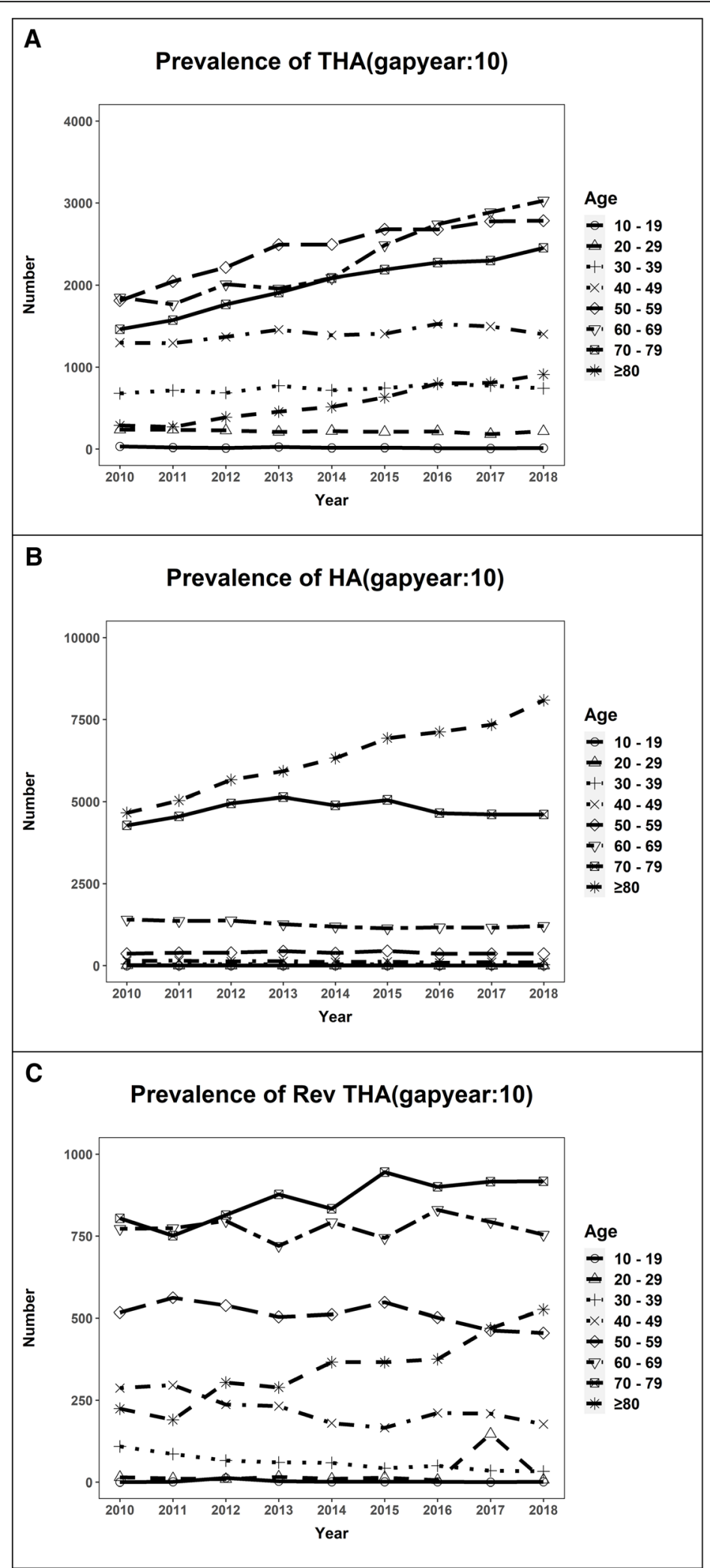

Fig. 2 Number of total hip arthroplasty a, hemiarthroplasty b, and revision total hip arthroplasty c stratified by age group from 2010 to 2018 (THA, total hip arthroplasty; HA, hemiarthroplasty; RevTHA, revision total hip arthroplasty) 


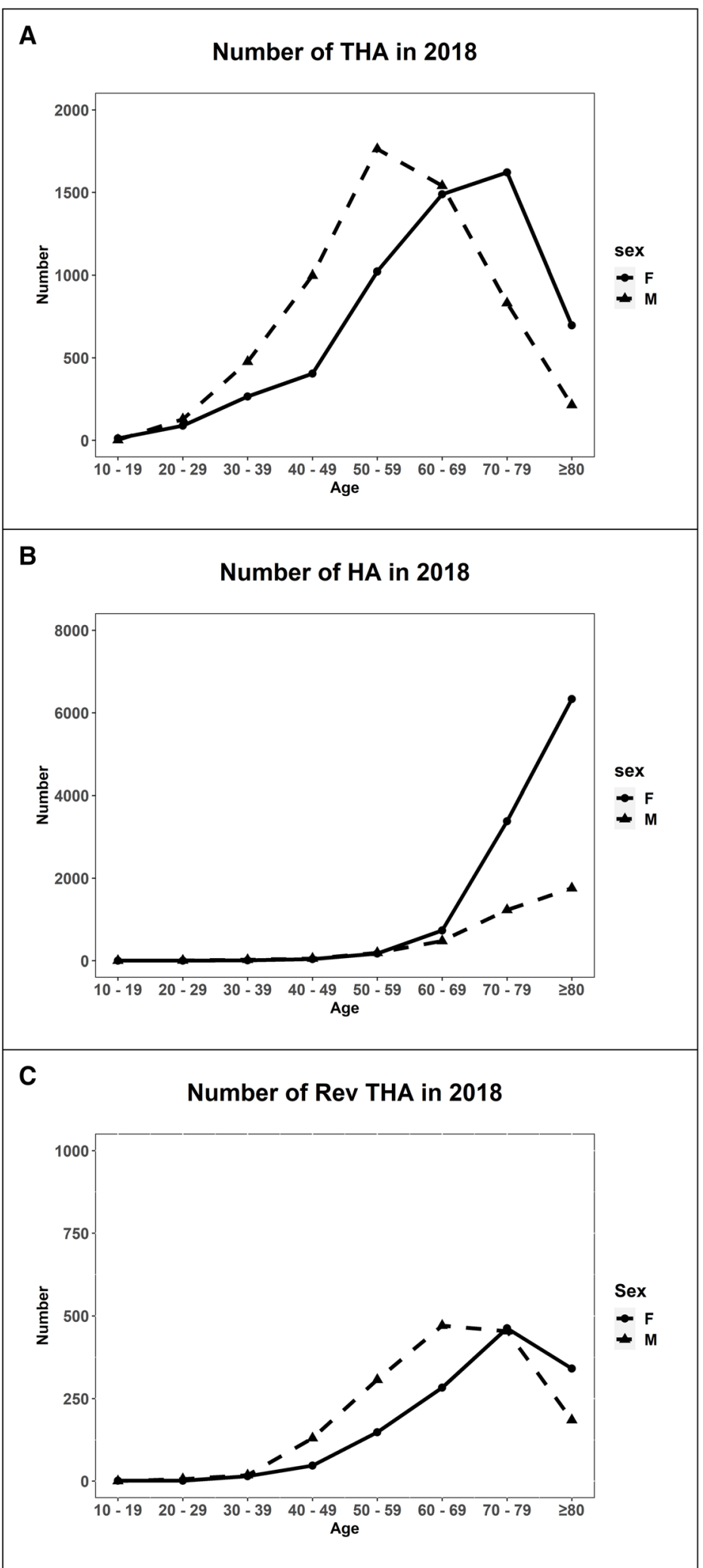

Fig. 3 Number of total hip arthroplasty $\mathbf{a}$, hemiarthroplasty $\mathbf{b}$, and revision total hip arthroplasty $\mathbf{c}$ in each age group in 2018 (THA, total hip arthroplasty; HA, hemiarthroplasty; RevTHA, revision total hip arthroplasty) 


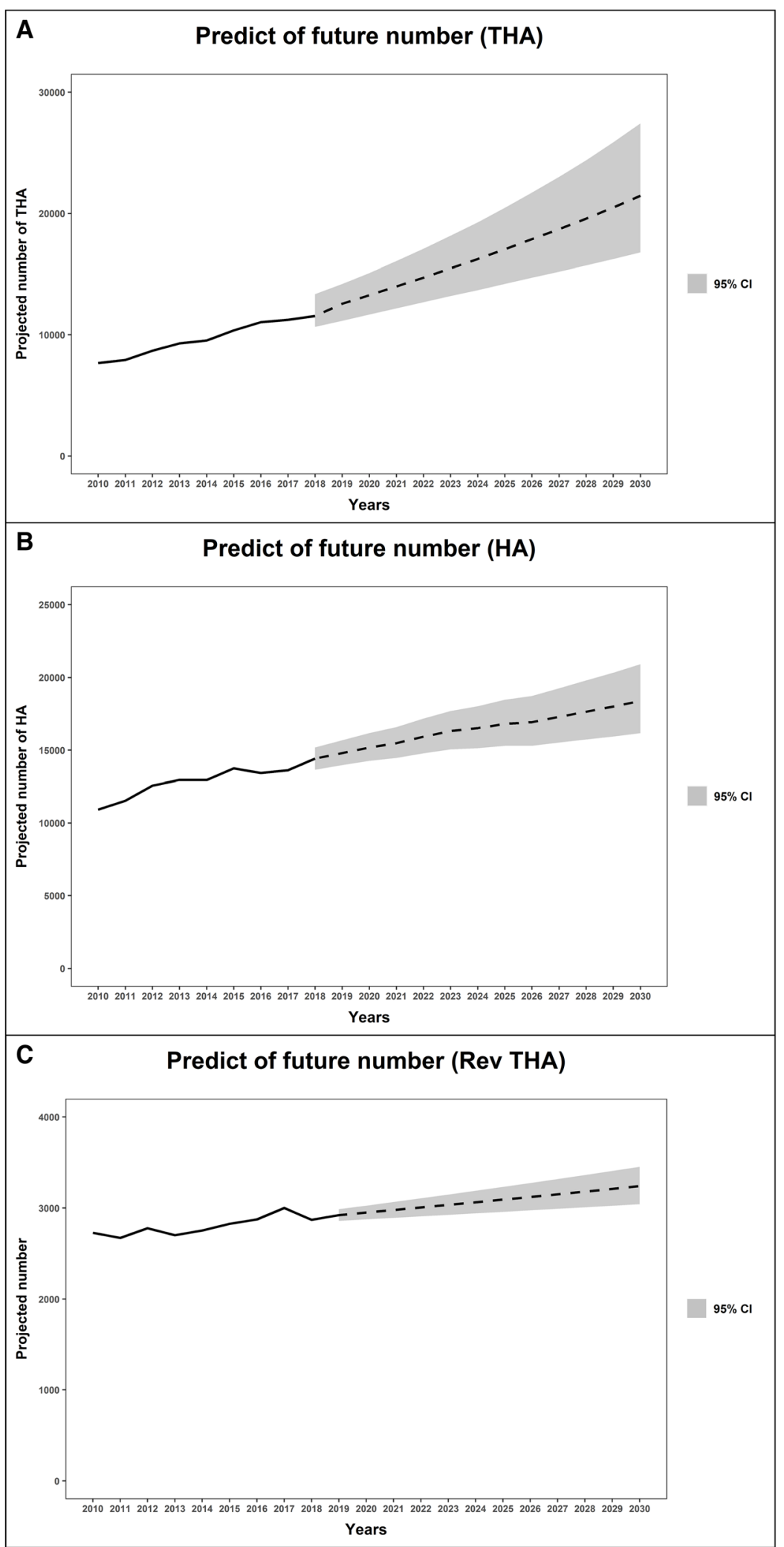

Fig. 4 Projection of future cases of total hip arthroplasty $\mathbf{a}$, hemiarthroplasty $\mathbf{b}$, and revision total hip arthroplasty $\mathbf{c}$ in South Korea (THA, total hip arthroplasty; HA, hemiarthroplasty; RevTHA, revision total hip arthroplasty) 
Table 3 Change of burden of revision total hip arthroplasty in each country

\begin{tabular}{llllll}
\hline Author & Country & Study period & Number of THA & Number of revision THA & Ratio of revision THA \\
\hline Wolf BR [19] & USA & $1991-2008$ & 188,646 to 279,627 & 48,528 to 57,331 & 0.20 to 0.17 \\
Kumar A [8] & Taiwan & $1998-2009$ & 3726 to 4972 & 931 to 968 & 0.20 to 0.16 \\
Kurtz SM [10] & USA & $2005-2015$ & 231,648 to 378,089 & 42,451 to 55,647 & 0.15 to 0.13 \\
Bozic KJ [2] & USA & $2006-2010$ & 222,239 to 291,994 & 40,555 to 49,857 & 0.15 to 0.15 \\
Patel A [15] & England \& Wales & $2008-2012$ & 71,077 to 79,949 & 7038 to 10,008 & 0.09 to 0.11 \\
Current study & Korea & $2010-2017$ & 7657 to 11,227 & 2728 to 3032 & 0.13 to 0.10
\end{tabular}

of the revision burden from 0.19 in 2001 to 0.13 in 2010 [21].

In 2014, Kurtz et al. estimated hip arthroplasty data of from the Nationwide Inpatient Sample in United States and projected the number of hip arthroplasties and the burden of revision THA. In their study, the number of primary THA and that of revision THA increased by $6.0 \%$ and by $10.8 \%$, respectively, and the revision burden increased from 0.135 to 0.141 from 2009 to 2010. The numbers were expected to increase by $74 \%$ for primary THA and 36\% for revision THA, but the revision burden was projected to decrease from 0.14 to 0.11 between 2010 and 2020 [9].

In 2019, Heckmann et al. compared the hip arthroplasty data from American Joint Replacement Registry (AJRR) to national registry data of Australia, New Zealand, England, Wales, Sweden and Norway [17]. In the AJRR, the burden of revision THA decreased from 0.14 in 2014 to 0.09 in 2016. The burden of revision THA decreased in most counties except for Norway. The burden decreased from 0.12 to 0.11 in Australia, from 0.15 to 0.12 in New Zealand, from 0.10 to 0.08 in England/Wales, and from 0.11 to 0.10 in Sweden [17]. However, in Norway, the burden slightly increased from 0.135 to 0.138 [17].

As opposed to the study of Heckmann et al., Patel et al. reported an increase of revision THA burden in England and Wales from 0.09 in 2008 to 0.11 in 2012 [14].

The annual incidence rate (per 100,000 person-year) of primary THA and revision THA increased from 101 to 134 and from 19.2 to 21.1 per 100,000 Danish inhabitants from 1996 to 2002, respectively. The incidence rates of primary THA and revision THA increased by 30 and $10 \%$ during the same period [15]. In line with this finding, the incidence of THA has also increased in South Korea during last decade. Aging of Korean population could be one of the main reasons of our findings.

In a previous study of THA epidemiology from South Korea, both the number and incidence rate of primary hip arthroplasty increased steadily from 2007 to 2011, but there was no significant change in the number of revision THA during the period [16].

The worldwide trend of decrease in the burden of revision THA (Table 3) means relatively small increase in the number of revision THAs compared to a substantial growth in the number of primary hip arthroplasties.

There might be some explanations for this decrease of the revision burden. First, surgical technique for primary THA has been improved with time [22]. Second, modern technologies of hip prostheses, especially, bearing surfaces might have prolonged the longevity of primary THA [23].

The strength of our study was that the study is based on national registry data. The results cover nearly $100 \%$ of all hip arthroplasties in South Korea. Such data are only available in few countries. Our study was based on national registry data and has inherent limitation. We could not identify the reason of arthroplasty, type of original prosthesis, type of fixation; cementless versus cemented, bearings surfaces and the reason of revision surgery in patients undergoing revision THA, because of de- identification of the HIRA database.

\section{Conclusions}

In this study, we confirmed an increase in number and incidence of revision THA as well as primary THA and HA from 2010 to 2018 in South Korea. The burden of revision THA in that period gradually decreased from 0.13 to 0.10 , which was similar to reports from Western countries.

\section{Abbreviations}

THA: Total hip arthroplasty; HA: Hemiarthroplasty; HIRA: Health Insurance and Review and Assessment; KNHIP: Korea National Health Insurance Program; EDI: Electronic Data Interchange; NHIS: National Health Insurance Service; Cl: Confidence interval; AJRR: American Joint Replacement Registry

\section{Supplementary Information}

The online version contains supplementary material available at https://doi. org/10.1186/s12891-021-04235-3.

Additional file 1. Complex conditions for reimbursement in arthroplasty in South Korea.

\section{Acknowledgements}

Jung-Wee Park and Seok-Hyung Won contributed equally to this study, and should be considered as co-first authors. funding from a grant of the Korea Health Technology R\&D Project through 
the Korea Health Industry Development Institute (KHIDI), funded by the Ministry of Health \& Welfare, Republic of Korea [grant number: HI18C0284].

\section{Authors' contributions}

JWP: writing - original draft, data curation. SHW: methodology, investigation. SYM: formal analysis, visualization. YKL: methodology, formal analysis. YCH: conceptualization, supervision. KHK: writing - review \& editing, supervision. The authors read and approved the final manuscript.

\section{Funding}

This study was funded by a grant of the Korea Health Technology R\&D Project through the Korea Health Industry Development Institute (KHIDI), funded by the Ministry of Health \& Welfare, Republic of Korea [grant number: HI18C0284]. The role of the funding by grant was in the access to and the analysis of the database.

\section{Availability of data and materials}

The datasets used and/or analyzed during the current study are available from the Korean Health Insurance and Review and Assessment (HIRA) database. https://opendata.hira.or.kr/home.do

\section{Declarations}

\section{Consent for publications}

Not applicable.

\section{Ethics approval and consent to participate}

The present study was exempted from institutional review board of the Seoul National University Bundang Hospital (IRB number: X-1907/555-902), because the database is opened to public, and does not include any individual's information.

\section{Competing interests}

The authors declare that they have no competing interests

\section{Author details}

${ }^{1}$ Department of Orthopaedic Surgery, Seoul National University Bundang Hospital, Seongnam, South Korea. 'Department of Public Health Science, Complex Disease and Genome Epidemiology Branch, School of Public Health, Seoul National University, Seoul, South Korea. ${ }^{3}$ Department of Orthopaedic Surgery, Chung-Ang University College of Medicine, Seoul, South Korea. ${ }^{4}$ Department of Orthopaedic Surgery, Seoul National University College of Medicine, Seoul, South Korea.

Received: 15 November 2020 Accepted: 9 April 2021

Published online: 22 April 2021

\section{References}

1. Berry DJ, Harmsen WS, Cabanela ME, Morrey BF. Twenty-five-year survivorship of two thousand consecutive primary Charnley total hip replacements: factors affecting survivorship of acetabular and femoral components. J Bone Joint Surg Am. 2002;84(2):171-7. https://doi.org/10.21 06/00004623-200202000-00002

2. Learmonth ID, Young $C$, Rorabeck $C$. The operation of the century: total hip replacement. Lancet. 2007;370(9597):1508-19. https://doi.org/10.1016/S01406736(07)60457-7.

3. Soderman P, Malchau H, Herberts P. Outcome after total hip arthroplasty: part I. general health evaluation in relation to definition of failure in the Swedish National Total hip Arthoplasty register. Acta Orthop Scand. 2000; 71(4):354-9. https://doi.org/10.1080/000164700317393330.

4. Soderman P, Malchau H, Herberts P, Zugner R, Regner H, Garellick G. Outcome after total hip arthroplasty: part II. Disease-specific follow-up and the Swedish National Total hip Arthroplasty Register. Acta Orthop Scand. 2001;72(2):113-9. https://doi.org/10.1080/000164701317323345.

5. Kurtz SM, Ong KL, Schmier J, Mowat F, Saleh K, Dybvik E, et al. Future clinical and economic impact of revision total hip and knee arthroplasty. J Bone Joint Surg Am. 2007;89(Suppl 3):144-51. https://doi.org/10.2106/JBJS.G. 00587.

6. Ong KL, Mowat FS, Chan N, Lau E, Halpern MT, Kurtz SM. Economic burden of revision hip and knee arthroplasty in Medicare enrollees. Clin Orthop Relat Res. 2006;446:22-8. https://doi.org/10.1097/01.blo.0000214439.95268.59.
7. Rudasill SE, Ng A, Kamath AF. Preoperative serum albumin levels predict treatment cost in Total hip and knee Arthroplasty. Clin Orthop Surg. 2018; 10(4):398-406. https://doi.org/10.4055/cios.2018.10.4.398.

8. Im C, Lee KJ, Min BW, Bae KC, Lee SW, Sohn HJ. Revision Total hip Arthroplasty after ceramic bearing fractures in patients under 60-years old; mid-term results. Hip Pelvis. 2018;30(3):156-61. https://doi.org/10.5371/hp.2 018.30.3.156.

9. Kurtz SM, Ong KL, Lau E, Bozic KJ. Impact of the economic downturn on total joint replacement demand in the United States: updated projections to 2021. J Bone Joint Surg Am. 2014;96(8):624-30. https://doi.org/10.2106/ JBJS.M.00285.

10. Kurtz S, Mowat F, Ong K, Chan N, Lau E, Halpern M. Prevalence of primary and revision total hip and knee arthroplasty in the United States from 1990 through 2002. J Bone Joint Surg Am. 2005;87(7):1487-97. https://doi.org/1 $0.2106 / J B J S . D .02441$

11. Hoaglund FT, Oishi CS, Gialamas GG. Extreme variations in racial rates of total hip arthroplasty for primary coxarthrosis: a population-based study in San Francisco. Ann Rheum Dis. 1995;54(2):107-10. https://doi.org/10.1136/a rd.54.2.107.

12. Ingvarsson T, Hagglund $\mathrm{G}$, Jonsson H Jr, Lohmander LS. Incidence of total hip replacement for primary osteoarthrosis in Iceland 1982-1996. Acta Orthop Scand. 1999;70(3):229-33. https://doi.org/10.3109/17453 679908997798.

13. Kumar A, Tsai WC, Tan TS, Kung PT, Chiu LT, Ku MC. Temporal trends in primary and revision total knee and hip replacement in Taiwan. J Chin Med Assoc. 2015;78(9):538-44. https://doi.org/10.1016/j.jcma.2015.06.005.

14. Patel A, Pavlou G, Mujica-Mota RE, Toms AD. The epidemiology of revision total knee and hip arthroplasty in England and Wales: a comparative analysis with projections for the United States. A study using the National Joint Registry dataset. Bone Joint J. 2015;97-B(8):1076-81. https://doi.org/1 0.1302/0301-620X.97B8.35170.

15. Pedersen AB, Johnsen SP, Overgaard S, Soballe K, Sorensen HT, Lucht U. Total hip arthroplasty in Denmark: incidence of primary operations and revisions during 1996-2002 and estimated future demands. Acta Orthop. 2005:76(2):182-9. https://doi.org/10.1080/00016470510030553.

16. Yoon PW, Lee YK, Ahn J, Jang EJ, Kim Y, Kwak HS, et al. Epidemiology of hip replacements in Korea from 2007 to 2011. J Korean Med Sci. 2014;29(6):8528. https://doi.org/10.3346/jkms.2014.29.6.852.

17. Heckmann $\mathrm{N}$, Ihn H, Stefl M, Etkin CD, Springer BD, Berry DJ, et al. Early results from the American joint replacement registry: a comparison with other National Registries. J Arthroplasty. 2019;34:S125-34 e121. https://doi. org/10.1016/j.arth.2018.12.027.

18. Malchau H, Herberts P, Eisler T, Garellick G, Soderman P. The Swedish Total hip replacement register. J Bone Joint Surg Am. 2002;84-A(Suppl 2):2-20. https://doi.org/10.2106/00004623-200200002-00002.

19. Wolf BR, Lu X, Li Y, Callaghan JJ, Cram P. Adverse outcomes in hip arthroplasty: long-term trends. J Bone Joint Surg Am. 2012;94(14):e103. https://doi.org/10.2106/JBJS.K.00011.

20. Bozic KJ, Kamath AF, Ong K, Lau E, Kurtz S, Chan V, et al. Comparative epidemiology of revision Arthroplasty: failed THA poses greater clinical and economic burdens than failed TKA. Clin Orthop Relat Res. 2015;473(6):21318. https://doi.org/10.1007/s11999-014-4078-8.

21. Schwartz BE, Piponov HI, Helder CW, Mayers WF, Gonzalez MH. Revision total hip arthroplasty in the United States: national trends and in-hospital outcomes. Int Orthop. 2016;40(9):1793-802. https://doi.org/10.1007/s00264016-3121-7.

22. Knight SR, Aujla R, Biswas SP. Total hip Arthroplasty - over 100 years of operative history. Orthop Rev (Pavia). 2011;3(2):e16. https://doi.org/10.4081/ or.2011.e16.

23. Hamilton WG, McAuley JP, Dennis DA, Murphy JA, Blumenfeld TJ, Politi J. THA with Delta ceramic on ceramic: results of a multicenter investigational device exemption trial. Clin Orthop Relat Res. 2010;468(2):358-66. https:// doi.org/10.1007/s11999-009-1091-4.

\section{Publisher's Note}

Springer Nature remains neutral with regard to jurisdictional claims in published maps and institutional affiliations. 